\section{Industrial Mineral Microscopy}

Louis P. Solebello, Research Microscopist McCrone Associates, Westmont, IL

What is industrial mineral microscopy? It is the application of any micro-analytical technique used to characterize and identify non-metallic and non-fuel earth materials. Humans have used industrial minerals since ancient times. The earliest known scientific work which dealt expressly with minerals and artificial products derived from them is Theophrastus on Stones. Theophrastus, a pupil and friend of Aristotle described the use of fuller's earth and gypsum for whitening discolored cloth garments in the latter half of the 4th century, B.C. Fuller's earth is still used today as a decolorizing agent by manufacturers of oil and fat products. Gypsum, of course, is widely used in plaster of paris, cement, and paper.

Today, industrial minerals are encountered often by people in everyday life. Electronic, pharmaceutical, cosmetic, construction, paper, and plastics industries use industrial minerals in a multitude of products. Familiar uses include talc in powders and deodorants and precipitated carbonates as extender, pigments, and fillers in paper and ploymers. Less common applications of industrial minerals are zeolites used as water softeners and molecular sieves, and micas as insulators for electrical components.

Companies that use industrial minerals are constantly looking for additional uses and ways to improve (beneficiate) industrial minerals. The role of the microscopist is to apply micro-analytical techniques which provide data and solve problems for companies that mine, beneficiate, and use industrial minerals. The mineral microscopist usually focuses on quality control, regulatory compliance, and product improvement or development

Quality control analyses frequently involve identification of contaminants in raw materials which are detrimental to the manufacture of final products. For example, one company recently experienced a costly nuisance when their screens became clogged during beneficiation of a talc ore. The client expressed concern that the contaminant might be cotton fibers or

\section{Diffraction Simulation and Analysis Software}

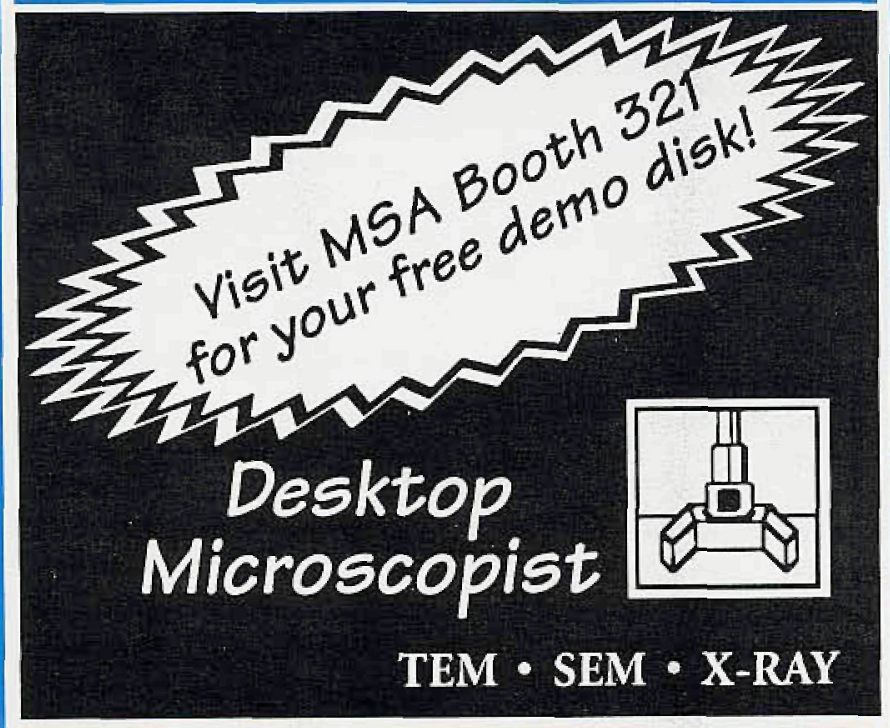

\footnotetext{
Virtual Laboratories

37 Highland Court - Ukiah, CA 95482 - USA

Tel: 707-462-8037 - Fax: 707-462-5275
}

chrysotile asbestos, which often occurs in stratigraphic horizons proximal to the talc where it is being mined. Examination of the fibers by polarized light microscopy (PLM) revealed that they were neither, but rather were talc fibers and ribbons (Figure 1). The client was relieved that there was no contaminant and, with this knowledge, modified their screening process to eliminate clogging problems. On one occasion, another talc beneficiator needed to identify black contaminant particles which they could not remove by magnetic separation. PLM analysis quickly identified the particles as graphite. The client was then able to effectively remove the undesired impurity by density separation.

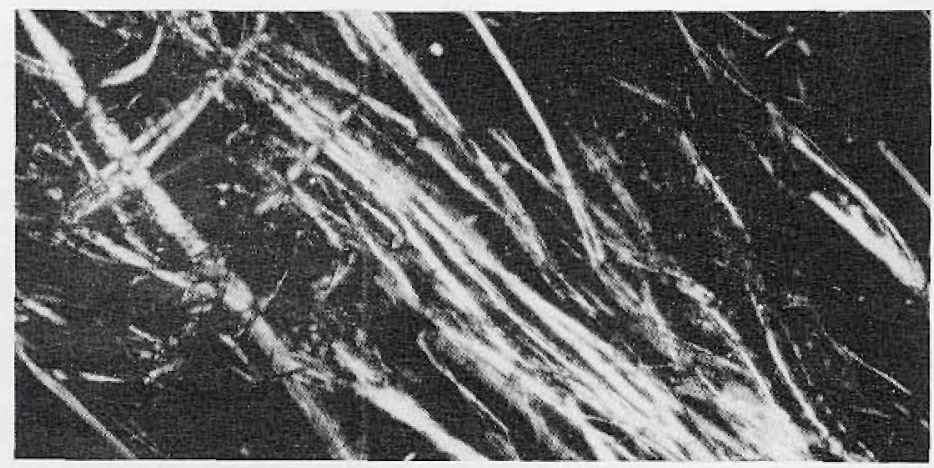

Figure 1: Talc Fibers and Ribbons

Regulatory compliance is an area that constantly challenges industrial mineral users to manufacture products in a responsible way so that they are environmentally safe to their employees and consumers. Asbestos and crystalline silica are perhaps the two materials of most concern to the general public. Recently, a manufacturer of a glass fiber woven insulation wrap needed to determine the crystalline silica content of their product to comply with OSHA regulations and meet product performance criteria. X-ray diffraction analysis (XRD) of samples heated at various temperatures and for different time periods quantified the total crystalline silica content (quartz, cristobalite, tridymite). With the data, the manufacturer could predict how the product would perform under specific applications and when it would exceed the permissible OSHA limit of $0.1 \%$ total crystalline silica.

Asbestos minerals continue to be a concern for companies that handle industrial minerals. Transmission electron microscopy (TEM) and $x$-ray diffraction are routinely used to determine the asbestos mineral content of talcs used by cosmetic and pharmaceutical companies. McCrone Associates, Inc. has performed these analyses for more than 25 years. Polarized light microscopy, when used by an experienced microscopist, can differentiate asbestos minerals from their non-asbestiform analogs and look-alike minerals. Fibers frequently encountered and mistaken for asbestos include sepiolite and attapulgite (fibrous clays), talc fibers and ribbons, and amphibole minerals that are not regulated as there is no current scientific evidence that they are carcinogenic.

The improvement and development of products often require that raw materials be characterized before and after incorporation into that product. One example is the beneficiation of a titanized mica to obtain a particle size distribution which produces a desired sheen in a bar of soap without imparting an undesirable gritty feel. Scanning electron microscopy (SEM) and polarized light microscopy can be used to determine the particle size distribution. X-ray diffraction is sometimes used to monitor phase transformation of raw materials and minerals in finished products subjected to controlled conditions designed to simulate product use or to enhance specific properties. Examples include the glass fiber woven wrap and the transformation of kaolinite to mullite and cristobalite in ceramic materials. PLM and SEM are used to examine changes in physical properties such as morphology, texture, color, microfracturing, and development of inclusions. All the information is pertinent to the manufacturer during improvement and development of a high quality finished product.

So, the next time you make a purchase, read the label and take some time to imagine how modern microscopy may have played a role in providing that product to you. Industrial minerals and microscopy have been an integral part of all our lives for some time and will continue to be for sometime to come in ways that we can only begin to imagine. 